\title{
Disparities in Research Studies and Their Impact on Marginalized Communities in Healthcare
}

\author{
Keelynn Grasse ${ }^{1}$ and Wes Collman ${ }^{1}$
}

${ }^{1}$ Georgetown High School, Georgetown, TX, USA

\section{ABSTRACT}

The United States healthcare system has been disproportionally affecting marginalized communities' healthcare due to the lack of diversity in research studies. These effects can be seen in the African American community, the population of women, and the LGBTQ+ community. Throughout history actions taken by healthcare officials, specifically researchers, have fostered a negative association within communities about studies. Which has resulted in a lack of volunteers and participation within marginalized communities and consequently heavily decreased the diversity needed to accurately represent populations in studies. This has created a rift in the accurateness of medical treatment that members of these communities' face. Without access to recent information that details specific reactions, officials are often not able to treat patients in marginalized groups with accurate data. This creates problems with patients receiving care that is not geared towards them and doctors not taking into account biological differences in patients. The necessity of diversity in studies is seen through the treatment of marginalized communities today when patients have to face medical officials who are misinformed about how to treat them. There is a distinct correlation between unsuccessful treatment and the lack of representation seen in research studies. Misinformation about marginalized communities is harmful to patients when they are trying to be treated and fosters negative feelings within these groups about healthcare officials. To stop perpetuating these ideas, medical officials need to become more active in gaining back marginalized communities' trust and advocating for representation in research studies as a necessity for quality healthcare.

\section{Introduction}

A rift in healthcare has become emphasized by the lack of representation in research studies. Workers often must compensate for their lack of knowledge when dealing with a certain community because the available information does not cover effects or information regarding these communities. Most often this results in discrepancies in the capability that healthcare professionals have in treating their patients. Women, African Americans, and LGBTQ+ members otherwise known as the lesbian, gay, bisexual, transgender, queer (sometimes questioning) plus community are groups that are directly impacted by this lack of research.

The lack of information increases the chance that doctors, or other medical professionals will inaccurately stereotype or diagnosis a member of one of those communities. Without studies done that portray an even sample of African Americans, women, and LGBTQ+ members healthcare officials must base their diagnoses on the stereotypical study representative, a white cisgender, someone whose gender aligns with their assigned sex, male (Dresser, 1992). This creates a definitive difference in how medical professionals respond to members of the other groups because they do not have any other information tested on someone other than that of the stereotypical white male.

Creating an environment where a white male is not a common research participant is essential in erasing biases in the medical community that prevent factual and reliable diagnoses. However, to accomplish that members of the healthcare community need to acknowledge discriminatory practices and laws that hinder African American, women, and LGBTQ+ member participation in studies. Understanding why there is an inconsistent representation of white men compared to marginalized communities is the first step in increasing diversity in research studies. 


\section{Women}

Women make up more than half of the United States population, yet in research studies that are not sex-specify the average enrollment of women makes up only $37 \%$ of participants (Greenwood et al., 2018). The lack of women representation is not as surprising as one would think, because men are still the traditional example used in Western medical books and information regarding women is often not as publicized (Dresser, 1992). This disproportion in studies should increase the number of women that researchers would like to study as such a significant population without a large information pool is detrimental to the healthcare system. However, it has shown that several factors make diversity difficult.

To achieve a better representation of the population in research studies there needs to be an equal portion of men and women to test the same product or medical treatment. Unofortunaley, when there is a tight research budget, women are oftentimes the ones excluded from the study instead of men (Holdcrofft, 2007). While the National Institutes of Health $(\mathrm{NIH})$ requires a more inclusive population in research studies, recruitment requires a large amount of money to encourage women to apply for these studies and the NIH has not provided adequate compensation (Brown et al., 2000). Researchers must then coordinate materials, participants, and additional factors while attempting to garner a larger sample of women in the study. Often this creates a large amount of stress that researchers have to deal with and fosters a lack of motivation to include women in studies (Brown et al., 2000). However, studies that are not NIH-funded are not more likely to include women in their studies. These investor groups often do not have gender diversity requirements in order to conduct a study (Somnath, 2015). Money is a substantial resource that researchers need so if there is not enough to conduct the study cuts are going to have to be made, frequently removing women from the research pool.

In the United States, a policy was enacted that helped studies become more male dominated on a basis regarding something other than funding. In 1977 the U.S. Food and Drug Administration passed a ban on women who were of child rearing age from certain drug tests even if they were single or their husbands had a vasectomy (Upham, 2020). Young women were excluded from all Phase 1 and Phase 2 drug tests until 1993 with the major fear that "the fetus would be damaged if [women] became pregnant during tests" and could not participate in any experiment unless it was a life-threatening disease (Hilts, 1993). This policy resulted in the complete ignorance of women of childbearing age, which encompasses teenagers through women who have not yet had menopause, and forced the healthcare community to generalize information that was only tested on older women or men. Without information that represents an age group that the general population of women is in for most of their life, diagnoses are at risk of being completely wrong or inconsistent.

This lack of women in research studies has consistently put women's health treatment at risk. Studies have shown that men and women's body composition react differently to different drugs or treatments, so without an accurate population sample, researchers will not know how a certain treatment affects women. For example, the U.S. Food and Drug Administration (FDA) had to decrease the dosage of Ambien, a drug to help induce sleep, for women because their slower metabolism did not have enough time to fully metabolize the medication and it was leading to severe side effects, like driving while asleep (Agoglia, 2019). This problem was missed in the clinical studies for the drug, but if a larger percentage of women had been in the research study the problem with Ambien would have been easier to catch (Agoglia, 2019). With Ambien it is apparent that the FDA did not find it as necessary to require the drug tested on women, or at least a large enough sample, then men because their dosage did not require any change. In fact, in 2005 "eight out of ten prescription drugs" were taken out of prescription markets in the United States because of their adverse effect on women's health (Holdcrofft, 2007). Overall, the standardization of drugs or other materials reviewed in studies needs to be reevaluated because men and women react differently to certain things and without incorporating for that difference it increases the health risk for women every time they take a drug.

Admittedly, studying men and women in different settings can also have a negative impact on reinforcing stereotypes. Men are traditionally seen as the standard for medical treatment and their reactions are viewed as normal or average, whereas women are viewed as more complex and "difficult" to treat and diagnose (Agoglia, 2019). This 
is damaging to women's health because frequently their symptoms are different to what men are demonstrating. However, medical professionals may view those symptoms as abnormal and not indicative of the same disease a man demonstrated with different symptoms.

Women and men have two distinctive biological systems and react to things differently, so it is essential that researchers acknowledge that factor and make sure each study has an equal ratio of both sexes. Without this accurate representation, women's health treatment is ignored in favor of cheaper and more male focused studies. While the United States' 1977 ban on women participating in drug studies has been repealed, women are still underrepresented in research and it is starkly apparent in healthcare.

\section{African American Population}

A history of manipulation and abuse has been the foundation of the relationship between the African American community and healthcare officials, specifically researchers, since the pre-Civil War era when slavery was prevalent in the United States' South. The repercussions of that experience have had wide reaching effects on the struggle to maintain an accurate population example in research studies. The hesitancy associated with researchers and medical professionals has been repeatedly enforced throughout African American's history with acts committed by the government and misinformation in the form of slander and inaccurate studies.

Experimentation committed by slave owners was the first historical example of the African American community losing their bodily autonomy in a research standard and was the starting point for their skepticism towards researchers. Slaves, without being given a chance to refuse, were required to follow what their owner ordered them to do, often at harm to themselves and this was taken advantage of by slave owners. For example, Thomas Hamilton forced a series of slaves to stay in a heated pit 5 to 6 times a day to test remedies for heatstroke (Gamble, 1997). This experimentation was not abnormal in the South and reduced African American slaves to liken a lab rat, which decisively fostered fear and hesitancy towards researchers and little participation in studies after the Civil War. Going into the modern age, this feeling continued within the African American community and only worsened with the Tuskegee Experiment.

The famous Tuskegee Experiment spanned from 1932 through 1972. This study focused on 600 African American sharecroppers, 399 of which had latent syphilis and 201 who did not, to observe the process of untreated syphilis. To encourage these participants to enroll in the experiment the U.S. Public Safety Service promised free medical care, however participants instead receive placebos instead of the recommended treatment of penicillin at the time (Nix, 2017). The program continued for 40 years with participants given no healthcare and no medical treatment as they "went blind or insane" or in 26 extreme cases passed away (Nix, 2017). The lack of information given to the participants and the subsequent lack of informed consent is one of the most significant examples of research abuse in the United States towards African Americans. This experiment resulted in an increase in "deep mistrust of public health officials" for the African American community and a significant decrease in applications for studies (Nix, 2017). Without applicants for research, there is no way for researchers to determine how certain drugs or treatment impact African Americas, decreasing precise information for medical professionals.

While distrust is a large reason there is a limited number of African Americans willing to apply for research study positions, other technical factors in the specific process of becoming a participant make it harder for those who would like to apply. For example, language barriers are consistent in various parts of the African American community in the United States who do not speak English coherently enough to answer specific medical questions or who do not understand the specific jargon and therefore cannot give an accurate response (Duran, 2014). Comprehension of material is critically important as the lack of informed consent was one of the biggest problems shown in the Tuskegee Experiment and rightfully the African American community is wary of that happening again. Additional factors like income, employment, and community safety also cause difficulty in gaining a diverse population of African Americans for research studies. For members of the African American population who have a low socioeconomic status, there is often an even higher level of distrust associated with healthcare professionals that make 
it difficult for engagement between each other (Armstrong, 2007). Additionally, with a low socioeconomic status comes general financial issues, such as the fact most insurances do not cover research or study related expenses and any expenses are left to the participant, which is often not a viable option for African Americans with a low-income status (Schmotzer, 2012). Transportation is also a major issue due to the fact oftentimes studies require participants to visit the research site multiple times, but those who do not have access to a car or a specific vehicle "create[s] an extra burden associated with [participants] care" and makes it difficult for them to attend studies (Schmotzer, 2012). Overall, many technical features decrease the already low amount of willing African Americans that would like to participant in research studies, and without accommodations African Americans that have a low socioeconomic status will be continuedly cut off from research studies.

Diversity in studies is so important because the limited amount of African American participation in research studies has led to a large amount of misinformation about the population. Oftentimes, this results in doctors and other medical professionals holding ideas or stereotypes about the African American community that are incorrect (i.e., increased aggression, lower level of intelligence, etc.) because there is not much accurate information available targeting African Americans (Guy-Walls et al., 2019). In fact, a study showed that medical students already hold "empirically false beliefs about race-based physiological differences," furthering stereotypical beliefs (Emanuel et al., 2020). These beliefs decrease overall medical care efficiency, not just of the medical side, because when African Americans believe they are part of a negatively stereotyped group they frequently feel threatened and may have "failures of self-regulation" or increased blood pressure and aggression (Aronson et al., 2013). These interactions have the possibility of increasing any existing conditions within African American patients and furthering any illogical stereotype. Without a comfortable environment African American patients may avoid their healthcare providers and consequently put themselves at a higher risk level to avoid a stereotype threat (Aronson et al., 2019). Decreasing misinformation like stereotypies is a key reason for increasing participation in research studies, with more information available the greater likelihood false stereotypes will be ignored.

Participation in research studies for African Americans has been diminished due to the levels of distrust associated with medical professionals and the government. The ignorance of technical factors like language and transportation makes it difficult to standardize medical procedures for African Americans also decrease participation. Without a large source of correct information, some medical professionals fall into a misinformation and stereotype trap which negatively affects their African American patients. To encourage participation in studies the medical community must try and breach the large gap between themselves and African American patients through community engagement and acknowledging there is a reason such a significant percentage of the African American population are hesitant to attend. With a healthy relationship with the African American community many patients will be more willing to participate in more research studies (Schmotzer, 2012). The information that will be gained regarding the African American population will make diagnosis easier and help make them comfortable in an environment that is historically uncomfortable.

\section{LGBTQ+ Community}

Targeting, a person, item, or place that is the subject of focus for the time being, is one of the first steps in starting and forming an experiment for the public. This idea allows the researcher to require specific standards for their study (i.e. age, behavior, traits, geographic area etc.) and helps them find ideal participants who will be comfortable in the experiment environment. However, this targeting increases the chance for discrimination for marginalized groups like the LGBTQ+ community.

There are many strategies to gather applicants for research studies like ads in newspapers, bulletin boards, or more commonly in this age is using different social media channels. These messages often come with information about the study such as the pay given, the date, where it is, and other general information. Some announcements describe specifics of who the researcher is looking for or who they are not looking for, and oftentimes being part of the LGBTQ+ community is a cause for rejection. For example, a study conducted by Brian Egleston, Roland Dunbrack 
Jr., and Michael Hall found that of 243 studies discovered using the keywords "couples," "erectile dysfunction," and "hypoactive sexual disorder," 15\% of them had specific exclusionary language against gay and lesbian couples (2010). This negative language limits the amount of LGBTQ+ members that can apply to be in studies, and thereby removes a significant population from testing while fostering bigotry in the research community.

Exclusionary language regarding LGBTQ+ members is common in determining participants for research studies, but studies who do not exclude members have inclusion problems as well. There is often a lack of appropriate questions pertaining to gender and sexual identity in most surveys for studies, which makes it more difficult for researchers and medical professionals alike to estimate the specific number of LGBTQ+ individuals and what their health care needs are ( 2 Hafeez et.al). However, surveys that do have specific questions regarding gender identity and sexuality do not foster much better. Oftentimes, participants that are part of the LGBTQ+ community will choose not to respond to the questions, drop out of the study, or answer incorrectly for fear of retaliation or discrimination (Institute of Medicine (US) Committee on Lesbian, Gay, Bisexual, and Transgender Health Issues and Research Gaps and Opportunities, 2011). Language that expresses diversity within gender identity and sexual orientation is beneficial for researchers, but the information needs to be delivered in a manner that acknowledges the negative history between LGBTQ+ members and the government.

Members of the LGBTQ+ community who choose to put forth their sexuality are normally "affirmative older LGBT people" who have come to terms with their sexuality and are able to confidently answer survey questions (Gay and Lesbian Medical Association and LGBT health experts, 2001). However, these older members of the community do not accurately portray the younger generation of the LGBTQ+ community and can give researchers specific information that cannot be generalized. Additionally, the factors that involve trying to reach these members often require a larger population pool and more resources to accurately find a substantial number of participants, which many researchers are hesitant to do (Institute of Medicine (US) Committee on Lesbian, Gay, Bisexual, and Transgender Health Issues and Research Gaps and Opportunities, 2011). With such a small LGBTQ+ population available for research studies, it puts researchers at a stalemate about how to achieve sexual and gender diversity in their studies for younger members that may have different reactions.

However, sexual and gender identity diversity is necessary for researchers to include and explore, because heightened discrimination in healthcare settings is associated with lack of information available that is LGBTQ+ inclusive. The constant fear associated with discrimination causes members of the LGBTQ+ community to suffer from higher rates of "depression, anxiety, suicidality, PTSD and other forms of psychological distress" and is encouraged by inaccurate prejudices (Frank \& Baker, 2019). Due to the discrimination at the hands of medical officials, many LGBTQ+ members do not seek care because they do not trust there would be equal treatment at the facility (Institute of Medicine (US) Committee on Lesbian, Gay, Bisexual, and Transgender Health Issues and Research Gaps and Opportunities, 2011). A healthy relationship between medical professionals and the LGBTQ+ community is critical in helping its members receive unbiased healthcare.

Having members of the LGBTQ+ population participating in research studies will decrease the ostracization that members of the community feel when faced with seeking any type of healthcare (Mizra et al., 2019). This is necessary to allow every member to receive essential healthcare, specifically transgender men and women, without increasing the side effects of discrimination. Additionally, common participation in studies will help to decrease the stigma and prejudice that medical professionals may have in relation to the LGBTQ+ community, while increasing representation and creating an environment that normalizes members of the LGBTQ+ community.

\section{Conclusion}

One must understand the healthcare repercussions of not including marginalized communities in research studies before trying to expand on research regarding the entire population. Without the ability to fund a study that accurately represents all members of the community, any non-specific research conducted has a high chance of ignoring crucial 
side effects or reactions for community members. This lack of understanding fosters a biased healthcare environment that African Americans, LGBTQ+ members, and women often feel not accurately represented in.

The research community has a long way to go to accurately present every marginalized community in studies, but the first step is making sure that these groups feel comfortable with healthcare professionals. Researchers need to undo the long and negative history associated between them and various communities for participation in studies to increase. By increasing funding or spreading awareness in the medical community, professionals can begin to specifically target these problems. With an increase in participation, misinformation can be prevented from doing any more harm to these marginalized communities and healthcare can begin to help and not harm.

\section{Acknowledgements}

I would like to thank my Capstone teacher, Mr. Collman, who pushed for this article's publication, and my two mentors, Mrs. Renee Koog, who assisted with the intensive editing process, and Dr. JT, who helped with the research portion of this process.

\section{References}

Agoglia, A. (2019, October 24). Missing Data: How the Exclusion of Female Subjects from Medical Research Hurts Science. The Pipettepen. http://www.thepipettepen.com/missing-data-how-the-exclusion-of-female-subjects-frommedical-research-hurts-science.

Armstrong, K., Ravenell, K. L., McMurphy, S., \& Putt, M. (2007). Racial/ethnic differences in physician distrust in the United States. American journal of public health, 97(7), 1283-1289. https://doi.org/10.2105/AJPH.2005.080762

Aronson, J., Burgess, D., Phelan, S. M., \& Juarez, L. (2013). Unhealthy interactions: the role of stereotype threat in health disparities. American journal of public health, 103(1), 50-56. https://doi.org/10.2105/AJPH.2012.300828

Brown, B. A., Long, H. L., Weitz, T. A., \& Milliken, N. (2000). Challenges of recruitment: focus groups with research study recruiters. Women \& health, 31(2-3), 153-166. https://doi.org/10.1300/j013v31n02_08

Egleston, B. L., Dunbrack, R. L., Jr, \& Hall, M. J. (2010). Clinical trials that explicitly exclude gay and lesbian patients. The New England journal of medicine, 362(11), 1054-1055. https://doi.org/10.1056/NEJMc0912600

Emanuel, E. J., \& Lavizzo-Mourey, R. (2020, September 24). 5 Ways the Health-Care System Can Stop Amplifying Racism. The Atlantic. https:/www.theatlantic.com/ideas/archive/2020/09/how-health-care-can-stop-amplifyingracism/616454/.

Gay and Lesbian Medical Association and LGBT health experts. (2001). Healthy People 2010 Companion Document for Lesbian, Gay, Bisexual, and Transgender (LGBT) Health. Gay and Lesbian Medical Association.

George, S., Duran, N., \& Norris, K. (2014). A systematic review of barriers and facilitators to minority research participation among African Americans, Latinos, Asian Americans, and Pacific Islanders. American journal of public health, 104(2), e16-e31. https://doi.org/10.2105/AJPH.2013.301706 
Greenwood, B. N., Carnahan, S., \& Huang, L. (2018, August 21). Patient-physician gender concordance and increased mortality among female heart attack patients. Proceedings of the National Academy of Sciences of the United States of America, 115 (34) 8569-8574. https://doi.org/10.1073/pnas.1800097115.

Hafeez, H., Zeshan, M., Tahir, M. A., Jahan, N., \& Naveed, S. (2017). Health Care Disparities Among Lesbian, Gay, Bisexual, and Transgender Youth: A Literature Review. Cureus, 9(4), e1184. https://doi.org/10.7759/cureus. 1184

Hilts, P. J. (1993, March 25). F.D.A. Ends Ban on Women in Drug Testing. https://www.nytimes.com/1993/03/25/us/fda-ends-ban-on-women-in-drug-testing.html.

Holdcroft, A. (2007). Gender bias in research: how does it affect evidence based medicine?. Journal of the Royal Society of Medicine, 100(1), 2-3. https://doi.org/10.1177/014107680710000102

Institute of Medicine (US) Committee on Lesbian, Gay, Bisexual, and Transgender Health Issues and Research Gaps and Opportunities. (2011). In Health of Lesbian, Gay, Bisexual, and Transgender People: Building a Foundation for Better Understanding. National Academies Press.

Mastroianni, A. C., Faden, R. R., \& Federman, D. (1999). Women and Health Research, Volume 2: Ethical and Legal Issues of Including Women in Clinical Studies: Workshop and Commissioned Papers. National Academies Press.

Mirza , S. A., \& Rooney, C. (2019, August 13). Discrimination Prevents LGBTQ People From Accessing Health Care. Center for American Progress. https://www.americanprogress.org/issues/lgbtqrights/news/2018/01/18/445130/discrimination-prevents-lgbtq-people-accessing-health-care/.

Nathaniel Frank, N., \& Baker, K. (2019, December 19). Perspective | Anti-LGBT discrimination has a huge human toll. Research proves it. The Washington Post. https://www.washingtonpost.com/outlook/2019/12/19/anti-lgbt-discrimination-has-huge-human-toll-research-proves-it/.

Nix, E. (2017, May 16). Tuskegee Experiment: The Infamous Syphilis Study. History.com. https://www.history.com/news/the-infamous-40-year-tuskegee-study.

Scharff, D. P., Mathews, K. J., Jackson, P., Hoffsuemmer, J., Martin, E., \& Edwards, D. (2010). More than Tuskegee: understanding mistrust about research participation. Journal of health care for the poor and underserved, 21(3), 879-897. https://doi.org/10.1353/hpu.0.0323

Schmotzer, G. L. Barriers and facilitators to participation of minorities in clinical trials. Ethnicity \& Disease. https://www.ethndis.org/edonline/index.php/ethndis/article/view/510/562.

Somnath Pal, B. S. (P. (2015, October 16). Inclusion of Women in Clinical Trials of New Drugs and Devices. U.S. Pharmacist - The Leading Journal in Pharmacy. https://www.uspharmacist.com/article/inclusion-of-women-in-clinical-trials-of-new-drugs-and-devices.

Taylor, E., Guy-Walls, P., Wilkerson, P. et al. The Historical Perspectives of Stereotypes on African-American Males. J. Hum. Rights Soc. Work 4, 213-225 (2019). https://doi.org/10.1007/s41134-019-00096-y 
Upham, Becky. (2020, February 18). Research Highlights Lack of Women Included in Cardiovascular Studies. Everyday Health. https://www.everydayhealth.com/heart-health/research-highlights-lack-of-women-included-in-cardiovascular-studies/ 